\title{
ANALISIS SPEKTRUM ENERGI DAN FUNGSI GELOMBANG POTENSIAL NON-CENTRAL MENGGUNAKAN SUPERSIMETRI MEKANIKA KUANTUM
}

\author{
Antomi Saregar \\ Pendidikan Fisika IAIN Raden Intan Lampung, E-mail: antomisaregar@radenintan.ac.id
}

Diterima: 12 Agustus 2015 Disetujui: 13 Oktober 2015. Dipublikasikan: Oktober 2015

\begin{abstract}
The objectives of this study were: 1) to describe the results of wave and energy function of the Non-central potential system of potential combinations of trigonometric Poschl-Teller plus Rosen Morse, Coloumb and $\mathrm{OH} 3 \mathrm{D}$ potential, and Rosen Morse trigonometric potential plus Pochl-Teller analyzed using Supersymmetry quantum mechanics (SUSY QM); 2) to know the visualization of wave function and energy level at point 1. This study is a literature study conducted from July 2013 to December 2015. Non-central potential of potential combinations of trigonometric Poschl-Teller potency plus Rosen Morse, Coloumb and $\mathrm{OH} 3 \mathrm{D}$ potential and potential Rosen Morse trigonometry plus Pochl-Teller is a potential that has a shape invariance properties. Recent developments, the SUSY method has been successfully used to create complete and precise mathematical analysis of the resolution of some non-central potentials in a closed system. By applying a lowering operator to a basic level wave function, a basic level wave function is obtained, while a top-level wave function is obtained by using a rising operator operated at a ground-level wave function and so on. While the value of energy in a closed system obtained by using the nature of the invariant shape.
\end{abstract}

\begin{abstract}
Abstrak: Tujuan Penelitian ini adalah: 1) mendeskripsikan hasil fungsi gelombang dan energi dari sistem potensial Non sentral hasil kombinasi potensial Poschl-Teller trigonometri plus potensial Rosen Morse, Coloumb, dan $\mathrm{OH} 3 \mathrm{D}$, serta potensial Rosen Morse trigonometri plus Pochl-Teller yang dianalisis menggunakan metode Supersymmetry mekanika kuantum (SUSY QM); 2) mengetahui visualisasidari fungsi gelombangdan tingkat energy pada poin 1. Penelitian ini merupakan studi literatur yang dilakukan mulai bulan Juli 2013 s.d. Desember 2015. Potensial non sentral hasil kombinasi potensial Poschl-Teller trigonometri plus potensial Rosen Morse, Coloumb, dan OH 3D serta potensial Rosen Morse trigonometri plus Pochl-Teller merupakan potensial yang mempunyai sifat shape invariance.Perkembangan terakhir, metode SUSY telah berhasil digunakan untuk membuat analisis matematis secara lengkap dan tepat penyelesaian beberapa potensial non sentral dalam sistem tertutup. Dengan mengaplikasikan operator penurun pada fungsi gelombang tingkat dasar diperoleh fungsi gelombang tingkat dasar, sedangkan fungsi gelombang tingkat atas satu diperoleh dengan menggunakan operator penaik yang dioperasikan pada fungsi gelombang tingkat dasar dan seterusnya. Sedangkan nilai energinya dalam sistem tertutup diperoleh dengan menggunakan sifat shape invariant.
\end{abstract}

Kata Kunci: coulomb, metode supersymmetry, $\mathrm{OH} 3 \mathrm{D}$, poschl-teller trigonometri, potensial non-sentral.

\section{PENDAHULUAN}

Salah satu tugas penting dari mekanika kuantum adalah menemukan solusi yang tepat dan akurat dari persamaan Schrödinger untuk potensial tertentu (Ballentine, 1999) (Gonul \& Kocak, 2005). Hal ini jelas bahwa mencari solusi yang tepat dari persamaan Schrödinger dengan metode biasa dan tradisional adalah mustahil untuk sistem fisika yang real, kecuali kasus-kasus tertentu seperti sistem atom hidrogen dan osilator harmonik (Gonul.B \& Zorba, 2000 at all.). Dengan demikian, tidak dapat dihindari penggunaan metode baru untuk membantu kita memecahkan sistem fisika yang real. Di antara kasuskasus di mana kita harus menolak metode biasa dan mencari metode baru, yakni dalam penyelesaian persamaan 
Schrödinger dengan potensial non sentral. Adapun, metode yang berbeda yang digunakan untuk memecahkan persamaan Schrödinger dengan potensial non sentral antara lain, metode faktorisasi, metode NU (Salehi, 2011), supersimetri (SUSY QM) (Ikhdair \& Sever, 2007), dan Romanovsky Polinomials (Suparmi at all, 2012). Supersymmetri, definisinya (Ranabir Dutt, 1988), adalah simetri antara fermion dan boson. Secara teori, supersimetri terdiri dari satu set bidang kuantum dan lagrangian,yang menunjukkan sifat simetri. Lagrangian ditentukan, melalui prinsip aksi persamaan gerak dan perilaku dinamis dari partikel. Teori supersimetri menggambarkan model partikel, dibuat dari medanvakum, dan interaksi antar partikel. Supersimetri memanifestasikan dirinya dalam spektrum partikel dan dalam hubungan antara proses interaksi yang berbeda bahkan jika ini melibatkan partikel spin yang berbeda dan statistik yang berbeda. Akhir-akhir ini, beberapa penulis telah menyelidiki pemecahan persamaan Schrödinger dengan beberapa potensial, diantaranya potensial PoschlTeller (Chen, 2001),potensial Noncentral (Yasuk at all, 2005; Saregar at all, 2013; Cari at all, 2014; Saregar, 2015), Potensial Hulthén plus Manning-Rosen (Meyur \& Debnath, 2009), potensial Rosen-Morse trigonometri plus Scarf (Meyur \& Debnath, 2010), potensial Eckart menggunakan metode NU (Gaudarzi, \& Vahidi, 2011) dan potensial Poschl-Teller trigonometri plus Rosen Morse dengan menggunakan polinomial Romanovsky (Gangopadhyaya, \& Sukhatme, 1996). Dalam makalah ini, kami menyelidiki nilai eigen energi dan fungsi gelombang dari sistem potensial Non sentral hasil kombinasi potensial Poschl-Teller trigonometri plus potensial Rosen Morse, dan Coloumb, serta potensial Rosen Morse trigonometri plus
Pochl-Teller yang dianalisis menggunakan metode Supersimetri mekanika kuantum (SUSY). PoschlTellertrigonometri digunakan untuk menggambarkan getaran molekul, sedangkan Rosen-Morse trigonometri potensial digunakan untuk menggambarkan esensi dari QCD quarkgluon dinamis, dalamderajat kebebasan asymptot dari quark (Salehi, 2011). Fungsi gelombang sudut yang divisualisasikan menggunakan Maple 12.

\section{METODE PENELITIAN \\ Tinjauan persamaan metode supersimetri mekanika kuantum}

Witten telah mendefiniskan SUSY mekanika kuantum sebagai suatu operator supermuatan $Q_{i}$ yang komut dengan SUSY Hamiltonian $\left(H_{S S}\right)$ dan operator supermuatan tersebut merupakan penyusun dari Hamiltonian (Mustafa \& Kais, 2009), yaitu:

$\left[Q_{i}, H_{s S}\right]=0$ dimana $i=1,2,3, \ldots \mathrm{N}(1)$ dan hubungan anti komut memenuhi $\left\{Q_{i}, Q_{j}\right\}=\delta_{i j} H_{s S}$, dimana $H_{s s}$ adalah SUSY Hamiltonian, dan $\mathrm{N}$ adalah bilangan pembangkit.

Operator super muatan $Q_{1} \operatorname{dan} Q_{2}$ dapat dihubungkan dengan spin $=1 / 2$ partikel yang bergerak pada satu garis (Suparmi, 2011). Terutama pada sistem ini, $Q_{i}$ dapat didefinisikan sebagai,

$$
\begin{aligned}
& Q_{1}=\frac{1}{\sqrt{2}}\left(\sigma_{1} \frac{p}{\sqrt{2 m}}+\right. \\
& \left.\sigma_{2} \phi(x)\right) \operatorname{dan} Q_{2}=\frac{1}{\sqrt{2}}\left(\sigma_{2} \frac{p}{\sqrt{2 m}}-\right. \\
& \left.\sigma_{1} \phi(x)\right)
\end{aligned}
$$

Dengan $\sigma_{i}$ merupakan matrik spin Pauli, dan $p=-i \hbar \frac{\partial}{\partial x}$ merupakan operator momentum linear. Sebagai contoh komponen $H_{S S}$ ditulis sebagai $H_{ \pm}$. Dengan menggunakan persamaan (1) dan (2) diperoleh: 


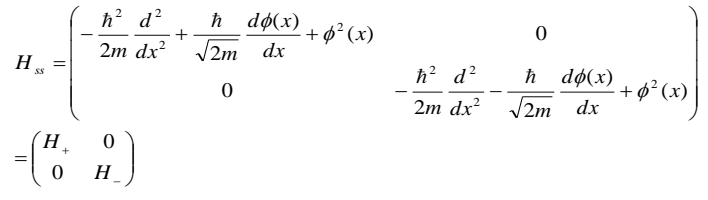

dengan,

$$
\begin{aligned}
& H_{-}=-\frac{\hbar^{2}}{2 m} \frac{d^{2}}{d x^{2}}+V_{-}(x), \text { dengan } \\
& V_{-}(x)=\phi^{2}(x)-\frac{\hbar}{\sqrt{2 m}} \phi^{\prime}(x)
\end{aligned}
$$

dan,

$$
\begin{aligned}
& H_{+}=-\frac{\hbar^{2}}{2 m} \frac{d^{2}}{d x^{2}}+V_{+}(x), \text { dengan } \\
& V_{+}(x)=\phi^{2}(x)+\frac{\hbar}{\sqrt{2 m}} \phi^{\prime}(x)
\end{aligned}
$$

Dengan $H_{-}$dan $H_{+}$didefinisikan sebagai pasangan Hamiltonian Penurun dan Hamiltonian Penaik, sedangkan $V_{-}(x)$ dan $V_{+}(x)$ merupakan pasangan potensial supersimetri.

Berdasarkan pers.(4a) dan (4b) persamaan Hamiltonian dapat difaktorkan menjadi,

$$
H_{-}=A^{+} A \quad \text {, dan } H_{+}=A A^{+}
$$

dengan, $A^{+}=-\frac{\hbar}{\sqrt{2 m}} \frac{d}{d x}+\phi(x)$ dan

$A=\frac{\hbar}{\sqrt{2 m}} \frac{d}{d x}+\phi(x)$

Dengan, $A^{+}$disebut operator penaik (raising operator), dan $A$ sebagai operator penurun (lowering operator).

\section{Potensial Shape Invariance}

Sepasang potensial supersimetri (SUSY), yaitu $V_{-}(x)$ dan $V_{+}(x)$ dapat Dari model teori potensial yang diusulkan Witten bahwa Hamiltonian didefinisikan sebagai kuadrat dari operator supermuatan yang kemudian dikembangkan sebagai hasil kali operator penaik dan penurun sehingga diperoleh Hamiltonian supersimetrik yang merupakan sepasang Hamiltonian $\mathrm{H}_{+}$dan H.. Sebagai akibatnya, masing-masing Hamiltonian terkait dengan potensial $\mathrm{V}_{+}$

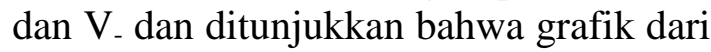
kedua potensial tersebut mempunyai bentuk yang sama walaupun tidak berimpit. Karena kedua potensial mempunyai bentuk yang sama maka sistem kuantum yang terkait dikatakan sebagai shape invariant potential system (Suparmi, 2011; Ballentine, 1999).

Pada bagian berikut ini akan kita lihat bagaimana eigenspectra dan eigenstate (eigenfunction) dari sekelompok Hamiltonian satu dimensi (atau sistem kuantum yang mempunyai dimensi lebih tinggi yang dapat di reduksi ke sistem satu dimensi) dapat dijabarkan secara aljabar dengan menggunakan ide shapeinvariance dan terkait dengan metode faktorisasi. Hamiltonian dari suatu sistem dengan spectrum diskrit dinyatakan sebagai

$$
V_{+}\left(x ; a_{j}\right)=V_{-}\left(x ; a_{j+1}\right)+R\left(a_{j+1}\right)
$$

dengan, $V_{+}\left(x ; a_{j}\right)=\phi^{2}\left(x, a_{j}\right)+$

$$
\begin{aligned}
& \frac{\hbar}{\sqrt{2 m}} \phi^{\prime}\left(x, a_{j}\right) \\
& V_{-}\left(x ; a_{j}\right)=\phi^{2}\left(x, a_{j}\right)-\frac{\hbar}{\sqrt{2 m}} \phi^{\prime}\left(x, a_{j}\right)
\end{aligned}
$$

dengan $j=0,1,2, .$. , sedangkan parameter $a$ ditentukan secara rekursif (berturutan), $a_{j+1}=f\left(a_{j}\right)$ dan $R\left(a_{j}\right)$ adalah konstanta yang tidak bergantung dengan $x$.

Hubungan antara Hamiltonian Standar dan Hamiltonian SUSY dinyatakan sebagai,

$$
\begin{aligned}
& H=H_{-}+E_{0}=-\frac{\hbar^{2}}{2 m} \frac{d^{2}}{d x^{2}}+ \\
& V_{-}\left(x ; a_{0}\right)+E_{0}
\end{aligned}
$$

Berdasarkan pers.(9) diperoleh hubungan antara $V(x)$ dan $V_{-}(x)$ sebagai berikut,

$V(x)=V_{-}\left(x ; a_{0}\right)+E_{0}=$

$\phi^{2}\left(x, a_{0}\right)-\frac{\hbar}{\sqrt{2 m}} \phi^{\prime}\left(x, a_{0}\right)+E_{0}$

$\operatorname{dimana} V(x)$ sering dinyatakan sebagai Potensial Efektif $\left(V_{e f f}\right)$. Sedangkan $\phi(x)$ ditentukan dengan dugaan secara intelektual berdasarkan bentuk potensial efektif sistem terkait.

Dengan mengulang prosedur sifat shape invariance, diperoleh generalisasi persamaan Hamiltonian sebagai berikut,

$H_{k}=-\frac{\hbar^{2}}{2 m} \frac{d^{2}}{d x^{2}}+V_{-}\left(x ; a_{k}\right)+$

$\sum_{i=1}^{k} R\left(a_{i}\right)$, dengan $k=0,1,2, \ldots$

Dengan membandingkan pers.(8) dan (9), diketahui bahwa $E_{0}^{(-)}=\sum_{i=1}^{k} R\left(a_{i}\right)$. 
Sehingga spektrum energi eigen nilai dari $H_{-}$dapat digeneralisasi menjadi,

$E_{n}^{(-)}=\sum_{k=1}^{n} R\left(a_{k}\right)$

Maka berdasarkan persamaan eigen nilai diperoleh,

$$
E_{n}=E_{n}^{(-)}+E_{0}
$$

dengan $E_{0}$ merupakan energi tingkat dasar pada pasangan hamiltonian penurun.

Berdasarkan sifat operator penurun, maka persamaan fungsi gelombang tingkat dasar dapat diperoleh dari persamaan,

$$
A \psi_{0}^{(-)}=0
$$

Sedangkan untuk fungsi gelombang tingkat atasnya satu dan seterusnya $\left(\psi_{n}^{-}\left(x ; a_{0}\right)\right)$ dapat ditentukankan dengan menggunakan operasi berantai operator penaik terhadap fungsi gelombang keadaan dasar $\psi_{0}^{-}\left(x ; a_{0}\right)$. Secara umum persamaan fungsi gelombang ini dapat dituliskan,

$\psi_{n}^{-}\left(x ; a_{0}\right) \sim A^{\dagger}\left(x ; a_{0}\right) \psi_{n-1}^{-}\left(x ; a_{1}\right)$

Potensial yang kami gunakan dalam penelitian ini adalah potensial non sentral hasil kombinasi potensial Poschl-Teller trigonometri plus potensial Rosen Morse, Coloumb, dan $\mathrm{OH} 3 \mathrm{D}$, serta potensial Rosen Morse trigonometri plus PochlTeller. Bentuk potensial non-sentral tersebut secara berurutan, ditunjukkan oleh persamaan,

$V_{(r, \theta)}=\frac{\hbar^{2}}{2 m \alpha^{2}}\left(\frac{v(v+1)}{\sin ^{2}\left(\frac{r}{\alpha}\right)}-\right.$

$\left.2 \mu \cot \left(\frac{r}{\alpha}\right)\right)+\frac{\hbar^{2}}{2 m r^{2}}\left(\frac{a(a-1)}{\sin ^{2} \theta}+\frac{b(b-1)}{\cos ^{2} \theta}\right)$

$V_{(r, \theta)}=-\frac{e^{2}}{r}+\frac{\hbar^{2}}{2 m r^{2}}\left(\frac{a(a-1)}{\sin ^{2} \theta}+\frac{b(b-1)}{\cos ^{2} \theta}\right)$...

$V_{(r, \theta)}=1 / 2 m \omega^{2} r^{2}+\frac{\hbar^{2}}{2 m r^{2}}\left(\frac{a(a-1)}{\sin ^{2} \theta}+\right.$

$\left.\frac{b(b-1)}{\cos ^{2} \theta}\right)$

$V_{(r, \theta)}=\frac{\hbar^{2}}{2 m \alpha^{2}}\left(\frac{a(a-1)}{\sin ^{2}\left(\frac{r}{\alpha}\right)}+\frac{b(b-1)}{\cos ^{2}\left(\frac{r}{\alpha}\right)}\right)+$

$\frac{\hbar^{2}}{2 m r^{2}}\left(\frac{v(v+1)}{\sin ^{2} \theta}-2 \mu \cot \theta\right)$

Dalam penelitian ini fungsi gelombang, dan spektrum energi potensialNon-
Sentral diselesaikan dengan metode SUSY.

Potensial non central dimodifikasi menjadi PS menggunakan koordinat bola.Setelah PS terbentuk, dengan menggunakan pemisahan variabel diperoleh persamaan radial, polar dan azimuth.Persamaan radial dan polar yang diperoleh diselesaikan dengan metode SUSY, sedangkan persamaan azimuth diselesaikan dengan persamaan diferensial orde dua.Dari fungsi radial yang diselesaikan dengan metode SUSY, diperoleh fungsi gelombang radial dan tingkat energi, dari fungsi polar diperoleh fungsi gelombang polar.Fungsi gelombang polar dan azimuth disatukan, menjadi fungsi gelombang sudut.

\section{HASIL DAN PEMBAHASAN}

a. Penyelesaian Persamaan Schrodinger Potensial Non-Sentral Kombinasi Potensial Rosen Morse Plus Potensial Poschl-Teller trigonometri dengan Menggunakan Metode Supersimetri

Bentuk persamaan Schrodinger untuk Potensial Rosen-Morse plus PoschlTeller trigonometri dinyatakan,

$-\frac{\hbar^{2}}{2 m}\left[\frac{1}{r^{2}} \frac{\partial}{\partial r}\left(r^{2} \frac{\partial \psi}{\partial r}\right)+\right.$

$\left.\frac{1}{r^{2} \sin \theta} \frac{\partial}{\partial \theta}\left(\sin \theta \frac{\partial \psi}{\partial \theta}\right)+\frac{1}{r^{2} \sin ^{2} \theta} \frac{\partial^{2} \psi}{\partial \varphi^{2}}\right]+$

$\frac{\hbar^{2}}{2 m \alpha^{2}}\left[\frac{v(v+1)}{\sin ^{2}\left(\frac{r}{\alpha}\right)}-2 \mu \cot \left(\frac{r}{\alpha}\right)\right] \psi+$

$\frac{\hbar^{2}}{2 m r^{2}}\left[\frac{a(a-1)}{\sin ^{2} \theta}+\frac{b(b-1)}{\cos ^{2} \theta}\right] \psi=E \psi$

Dari pers.(20) diperoleh persamaan Schrodinger bagian fungsi bagian radial dan sudut dan adzimut, secara berurutan dalam bentuk,

$\frac{1}{r^{3}} \frac{\partial}{\partial r}\left(r^{2} \frac{\partial}{\partial r}\left(\frac{\chi}{r}\right)\right)-\frac{1}{r \alpha^{2}}\left[\frac{v(v+1)}{\sin ^{2}\left(\frac{r}{\alpha}\right)}-\right.$

$\left.2 \mu \cot \left(\frac{r}{\alpha}\right)\right] \chi-\frac{l(l+1)}{r^{3}} \chi+\frac{2 m}{r \hbar^{2}} E \chi=0$ 
$-\frac{\hbar^{2}}{2 m} \frac{d^{2} H}{d \theta^{2}}+\frac{\hbar^{2}}{2 m}\left(\frac{a(a-1)+m^{2}-\frac{1}{4}}{\sin ^{2} \theta}+\frac{b(b-1)}{\cos ^{2} \theta}\right) H=$ $\frac{\hbar^{2}}{2 m}\left(l(l+1)+\frac{1}{4}\right) \ldots . .(22)$

$\Phi=\sqrt{\frac{1}{2 \pi}} \mathrm{e}^{\mathrm{im} \varphi}$

Kemudian kita selesaikan persamaan bagian radial terlebih dahulu. Dari pers.(21) diperoleh potensial efektif dalam bentuk,

$V_{\text {eff }}=\frac{\hbar^{2}}{2 m \alpha^{2}}\left[\frac{v \prime(v \prime+1)}{\sin ^{2}\left(\frac{r}{\alpha}\right)}-2 \mu \cot \left(\frac{r}{\alpha}\right)\right]+$

$\frac{\hbar^{2}}{2 m \alpha^{2}} l(l+1) d_{0}$

dengan $v^{\prime}=\sqrt{v(v+1)+l(l+1)+\frac{1}{4}}-\frac{1}{2}$

Dengan memasukkan potensial efektif pada pers (24) kedalam pers (2.14) diperoleh,

$\phi_{0}^{2}(x)-\frac{\hbar}{(2 m)^{1 / 2}} \phi_{0}^{\prime}(x)=\frac{\hbar^{2}}{2 m \alpha^{2}}\left[\frac{v r(v /+1)}{\sin ^{2}\left(\frac{r}{\alpha}\right)}-\right.$

$\left.2 \mu \cot \left(\frac{r}{\alpha}\right)\right]+\frac{\hbar^{2}}{2 m \alpha^{2}} l(l+1) d_{0}-E_{0}$

dengan menggunakan dugaan yang tajam (yang telah terlatih), maka dimisalkan superpotensial dari pers (24) adalah,

$\phi(x)=A \cot \left(\frac{r}{\alpha}\right)-\frac{B}{A}$

Dengan menggunakan pers. (2.9) dan (25) diperoleh

$A^{\dagger}=-\frac{\hbar}{\sqrt{2 m}} \frac{d}{d r}+\phi(r)=$

$-\frac{\hbar}{\sqrt{2 m}} \frac{d}{d r}-\frac{\hbar}{\alpha(2 m)^{\frac{1}{2}}}\left(\left(v^{\prime}+\right.\right.$

1) $\left.\cot \left(\frac{r}{\alpha}\right)-\frac{\mu}{\left(v^{\prime}+1\right)}\right)$

Dan

$A=\frac{\hbar}{\sqrt{2 m}} \frac{d}{d r}+\phi(r)=\frac{\hbar}{\sqrt{2 m}} \frac{d}{d r}-$

$\frac{\hbar}{\alpha(2 m)^{\frac{1}{2}}}\left(\left(v^{\prime}+1\right) \cot \left(\frac{r}{\alpha}\right)-\frac{\mu}{\left(v^{\prime}+1\right)}\right)$

Sehingga diperoleh fungsi gelombang tingkat dasarnya ditulis,

$\psi_{0}{ }^{(-)}=$

$C\left(\sin \left(\frac{r}{\alpha}\right)\right)^{\left(v^{\prime}+1\right)} \exp \left(-\frac{\mu r}{\alpha\left(v^{\prime}+1\right)}\right) \ldots$

dengan menggunakan persamaan (2.19) kita peroleh fungsi gelombang sistem yang tereksitasi tingkat pertama yaitu

$\psi_{1}{ }^{(-)}\left(x ; a_{0}\right) \sim A^{\dagger}\left(x ; a_{0}\right) \psi_{0}^{-}\left(x ; a_{1}\right)(29)$ dapat ditulis kembali solusi energi persamaan Schrodinger untuk potensial non sentral Rosen Morse plus PoschlTeller sebagai

$E_{n_{r}}=\frac{\hbar^{2}}{2 m \alpha^{2}}\left[\left(\sqrt{v(v+1)+l(l+1)+\frac{1}{4}}+\right.\right.$

$\left.n_{r}+\frac{1}{2}\right)^{2}+l(l+1) d_{0}-$

$\left.\frac{\mu^{2}}{\left(\sqrt{v(v+1)+l(l+1)+\frac{1}{4}}+n_{r}+\frac{1}{2}\right)^{2}}\right]$

Dari pers.(30), diperoleh grafik tingkat energi untuk potensial non-sentral Poschl-Teller trigonometri plus Rosen Morse, dalam bentuk,

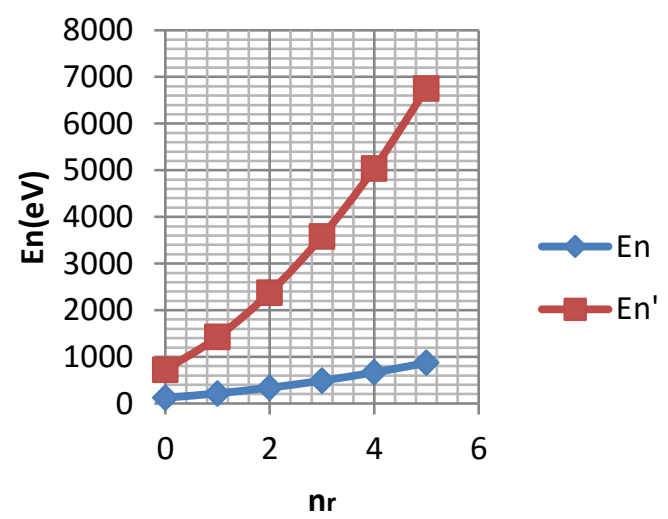

Gambar 1.Grafik Tingkat Energi Potensial Non Sentral Poschl Teller Trigonometri plus Rosen Morse, dengan $\mathrm{m}=1$, $n_{l}=1, \mu=1, v=2$, dan $n_{r}=$ $0,1,2,3,4,5$.

Gambar 1 menunjukan bahwa harga bilangan kuantum orbital dipengaruhi oleh nilai $l$, dengan $\mathrm{m}, n_{l}, \mu$ dan $v$ konstan. Basarnya nilai $l$ menentukan kapasitas gangguan dari potensial Poschl Teller, dalam hal ini, semakin besar harga $l$, potensial Rosen Morse akan mengalami gangguan yang semakin besar dari potensial Poschl Teller.

Untuk mempermudah penyelesaian persamaan Schrodinger bagian sudut, dimisalkan, 


$$
\frac{\hbar^{2}}{2 m}\left(l(l+1)+\frac{1}{4}\right) H=E H
$$

Potensial effektif dari potensial Resen Morse plus Potensial Poschl-Teller bagian sudut dituliskan sebagai

$$
V_{e f f}=\frac{\hbar^{2}}{2 m}\left(\left(\frac{a(a-1)+m^{2}-\frac{1}{4}}{\sin ^{2} \theta}+\frac{b(b-1)}{\cos ^{2} \theta}\right)\right.
$$

Berdasarkan bentuk persamaan potensial efektif tersebut, maka persamaan superpotensial untuk Potensial Rosen morse plus Potensial Poschl-Teller bagian sudut dapat dimisalkan sebagai,

$$
\phi(\theta)=A \tan \theta+B \cot \theta
$$

Sehingga diperoleh spektrum energi untuk sistem Poschl-Teller yaitu,

$$
E_{n}=\frac{\hbar^{2}}{2 m}\left(b+a^{\prime}+2 n\right)^{2}
$$

dengan $a^{\prime}=\sqrt{a(a-1)+m^{2}}+\frac{1}{2}$

Dengan menggunakan parameter berorde energi yang sama dengan eigen nilai dari kuadrat momentum sudut seperti yang dinyatakan pada pers. (34) maka diperoleh bilangan kuantum sudut yang dinyatakan sebagai,

$$
\begin{aligned}
& \left(l(l+1)+\frac{1}{4}\right)=\left(\sqrt{a(a-1)+m^{2}}+\frac{1}{2}+\right. \\
& b+2 n)^{2}
\end{aligned}
$$

Maka $l=\sqrt{a(a-1)+m^{2}}+b+2 n$

Selanjutnya, dengan menggunakan operator penurun ditentukan fungsi gelombang tingkat dasar untuk potensial non-sentral Rosen Morse plus PoschlTeller bagian sudut, yang bentuknya

$$
\begin{aligned}
& \psi_{0}{ }^{(-)}=C(\cos \theta)^{b}(\sin \theta)^{a \prime}= \\
& (\cos \theta)^{b}(\sin \theta)^{\sqrt{a(a-1)+m^{2}}+\frac{1}{2}}
\end{aligned}
$$

Sedangkan untuk fungsi gelombang tereksitasi bisa dicari menggunakan operator penaik.
Tabel 1. Hasil perhitungan fungsi gelombang polar potensial non sentral Poschl Teller plus Rosen Morse

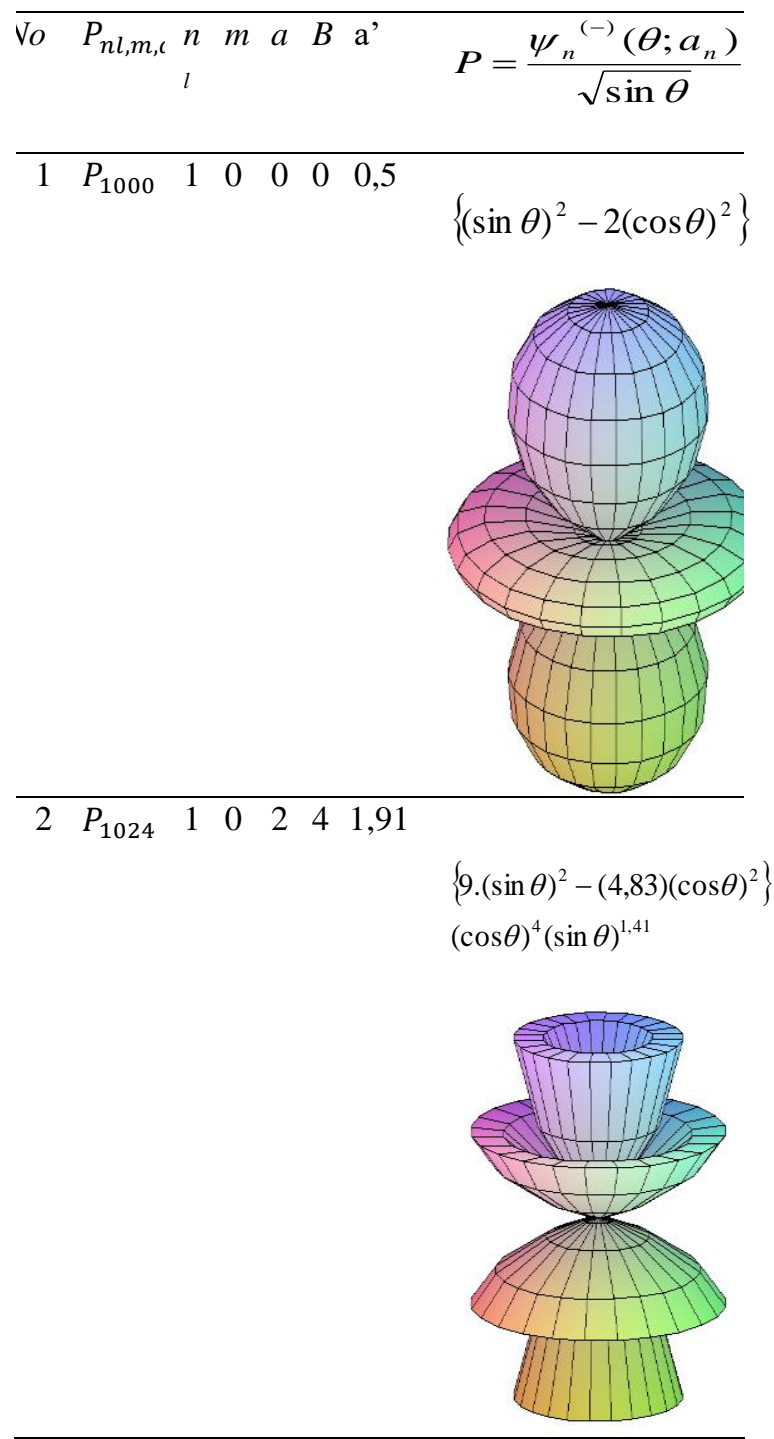

Tabel 1. menunjukkan bentuk fungsi gelombang polar berkaitan dengan arah momentum sudut spin elektron serta melukiskan ketergantungan rapat probabilitas pada sudut. Secara umum definisi fungsi gelombang polar sama dengan fungsi gelombang radial yaitu menyatakan probabilitas ditemukan elektron, namun keduanya memiliki perbedaannya pada pergerakannya jika fungsi gelombang radial berkaitan dengan menjauh atau mendekatnya elektron dari inti, maka fungsi 
gelombang polar berkaitan dengan putaran elektron terhadap inti.

b. Penyelesaian Persamaan Schrodinger Potensial Non-Sentral Kombinasi Potensial Coulomb Plus Potensial Poschl-Teller trigonometri dengan Menggunakan Metode Supersimetri

Mengikuti prosedur pada poin a, diperoleh persamaan Schrodinger bagian radial, sudut, dan adzimut, secara berurutan ditulis,

$-\frac{\hbar^{2}}{2 m} \frac{\partial^{2} \chi}{\partial r^{2}}+\frac{\hbar^{2}}{2 m} \frac{l(l+1)}{r^{2}} \chi-\frac{e^{2}}{r} \chi=E \chi$

$-\frac{\hbar^{2}}{2 m} \frac{d^{2} H}{d \theta^{2}}+\frac{\hbar^{2}}{2 m}\left(\frac{a(a-1)+m^{2}-\frac{1}{4}}{\sin ^{2} \theta}+\right.$

$\left.\frac{b(b-1)}{\cos ^{2} \theta}\right) H=\frac{\hbar^{2}}{2 m}\left(l(l+1)+\frac{1}{4}\right) H$

$\Phi=\sqrt{\frac{1}{2 \pi}} \mathrm{e}^{\mathrm{im} \varphi}$

Penyelesaian bagian radial pada poin $b$, sehingga diperoleh potensial effektif,

$V_{\text {eff }}=\frac{\hbar^{2}}{2 m} \frac{l(l+1)}{r^{2}}-\frac{e^{2}}{r}$

Dengan

permisalan

superpotensialnya,

$\phi(x)=A+\frac{B}{r}$

sehingga diperoleh fungsi gelombang tingkat dasar, dengan bentuk,

$\psi_{0}{ }^{(-)}=C r^{(l+1)} \exp \left(-\frac{m r}{\hbar^{2}(l+1)} e^{2}\right)$

dan fungsi gelombang tereksitasi tingkat pertama, dengan bentuk,

$$
\begin{aligned}
& \psi_{1}{ }^{(-)}\left(x ; a_{0}\right)= \\
& -\frac{\hbar}{\sqrt{2 m}}\left\{\left(\frac{(l+2)}{r}\right)-\frac{m}{\hbar^{2}(l+2)} e^{2}-\frac{m}{\hbar^{2}(l+1)} e^{2}+\right. \\
& \left.\frac{(l+1)}{r}\right\}\left\{C r^{(l+2)} \exp \left(-\frac{m r}{\hbar^{2}(l+2)} e^{2}\right)\right\}
\end{aligned}
$$

dan dengan proses yang sama pada poin a, maka diperoleh spektrum energi untuk sistem Coulomb,

$$
E_{n_{r}}=-\frac{m}{2 \hbar^{2}\left(l+n_{r}+1\right)^{2}} e^{4}
$$

dari pers.(44), diperoleh grafik tingkat energi untuk potensial non-sentral Poschl-Teller trigonometri plus Coulomb, dalam bentuk,

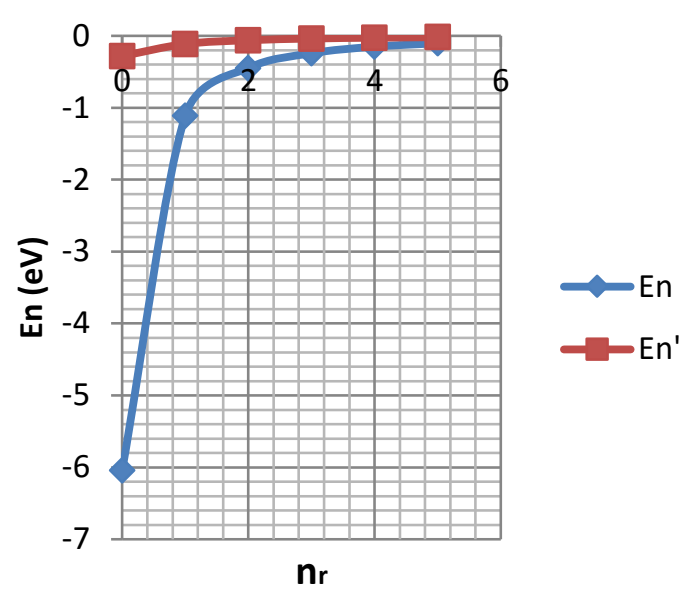

Gambar 2. Grafik Tingkat Energi Potensial Non Sentral Poschl Teller Trigonometri plus Coulomb, dengan $\mathrm{m}=1, n_{l}=$ 1,dan $n_{r}=0,1,2,3,4,5$.

Gambar 2. menunjukkan bahwa harga bilangan kuantum orbital dipengaruhi oleh nilai $l$, dengan $\mathrm{m}$ dan $n_{l}$ konstan. Basarnya nilai $l$ menentukan kapasitas gangguan dari potensial Poschl Teller, dalam hal ini, semakin besar harga $l$, potensial Coulomb akan mengalami gangguan yang semakin besar dari potensial Poschl Teller.

Sedangkan penyelesaian persamaan schrodinger potensial Coulomb plus Poschl-Teller trigonometri bagian sudut hasilnya sama dengan penyelesaian bagian sudut potensial Poschl Teller trigonometri pada poin a, sehingga tidak perlu dijabarkan kembali pada bahasan ini.

c. Penyelesaian Persamaan Schrodinger Potensial Non-Sentral Kombinasi Potensial $\mathrm{OH}$ 3D Plus Potensial Poschl-Teller trigonometri dengan Menggunakan Metode Supersimetri

Mengikuti prosedur pada poin a, diperoleh persamaan Schrodinger bagian radial, sudut, dan adzimut, secara berurutan ditulis, 
$-\frac{\hbar^{2}}{2 m} \frac{\partial^{2} \chi}{\partial r^{2}}+\frac{1}{2} m \omega^{2} r^{2} \chi+\frac{\hbar^{2}}{2 m} \frac{l(l+1)}{r^{2}} \chi=E \chi$

$-\frac{\hbar^{2}}{2 m} \frac{d^{2} H}{d \theta^{2}}+\frac{\hbar^{2}}{2 m}\left(\frac{a(a-1)+m^{2}-\frac{1}{4}}{\sin ^{2} \theta}+\frac{b(b-1)}{\cos ^{2} \theta}\right) H=$ $\frac{\hbar^{2}}{2 m}\left(l(l+1)+\frac{1}{4}\right) H$

$$
\Phi=\sqrt{\frac{1}{2 \pi}} \mathrm{e}^{\mathrm{im} \varphi}
$$

Penyelesaian bagian radial pada poin c, sehingga diperoleh potensial effektif,

$$
V_{\text {eff }}=\frac{1}{2} m \omega^{2} r^{2}+\frac{\hbar^{2}}{2 m} \frac{l(l+1)}{r^{2}}
$$

Dengan permisalan superpotensialnya,

$$
\phi(x)=A r+\frac{B}{r}
$$

Sehingga diperoleh fungsi gelombang tingkat dasar, dengan bentuk,

$$
\psi_{0}^{(-)}=C r^{(l+1)} \exp \left(-\frac{1}{2} \frac{m \omega r^{2}}{\hbar}\right)
$$

Dan fungsi gelombang tereksitasi tingkat pertama, dengan bentuk,

$$
\begin{aligned}
& \psi_{1}^{(-)}\left(x ; a_{0}\right)=\frac{2 \hbar}{\sqrt{2 m}}\left\{\frac{m \omega r^{2}}{\hbar}-(l+\right. \\
& \left.\left.\frac{3}{2}\right)\right\}\left\{\operatorname{Cr}^{(l+1)} \exp \left(-\frac{1}{2} \frac{m \omega r^{2}}{\hbar}\right)\right\}
\end{aligned}
$$

dan dengan proses yang sama pada poin a, maka diperoleh spektrum energi untuk sistem Coulomb yaitu,

$$
E_{n_{r}}=\hbar \omega\left(2 n_{r}+l+\frac{3}{2}\right)
$$

dari pers.(52), diperoleh grafik tingkat energi untuk potensial non-sentral Poschl-Teller trigonometri plus $\mathrm{OH} 3 \mathrm{D}$, dalam bentuk

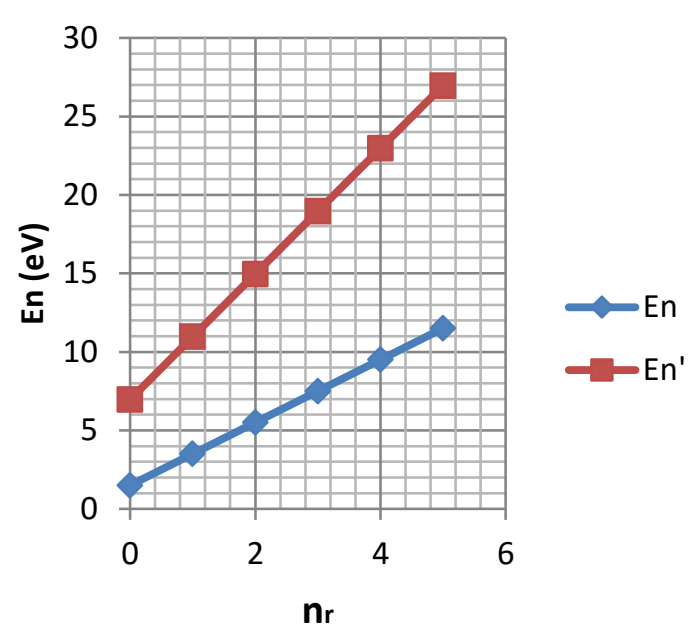

Gambar 3. Grafik Tingkat Energi Potensial Non Sentral Poschl Teller Trigonometri plus $\mathrm{OH} 3 \mathrm{D}$, dengan $\mathrm{m}=1, n_{l}=1$, dan $n_{r}=0,1,2,3,4,5$.

Gambar 3, menunjukkan bahwa harga bilangan kuantum orbital dipengaruhi oleh nilai $l$, dengan $\mathrm{m}$ dan $n_{l}$ konstan. Basarnya nilai $l$ menentukan kapasitas gangguan dari potensial Poschl Teller, dalam hal ini, semakin besar harga $l$, potensial $\mathrm{OH} 3 \mathrm{D}$ akan mengalami gangguan yang semakin besar dari potensial Poschl Teller.

d. Penyelesaian Persamaan Schrodinger Potensial Non-Sentral Kombinasi Potensial Rosen Morse trigonometri Plus Potensial Poschl-Teller dengan Menggunakan Metode Supersimetri

Mengikuti prosedur pada poin a, diperoleh persamaan Schrodinger bagian radial, sudut, dan adzimut, secara berurutan ditulis,

$$
\begin{aligned}
& -\frac{\hbar^{2}}{2 m} \frac{\partial^{2} \chi}{\partial r^{2}}+\frac{\hbar^{2}}{2 m \alpha^{2}}\left(\frac{a(a-1)}{\sin ^{2}\left(\frac{r}{\alpha}\right)}+\right. \\
& \left.\frac{b(b-1)}{\cos ^{2}\left(\frac{r}{\alpha}\right)}\right) \chi+\frac{\hbar^{2}}{2 m \alpha^{2}} l(l+1) d_{0} \chi= \\
& -\frac{\hbar^{2}}{2 m} \epsilon^{2} \chi \\
& -\frac{\hbar^{2}}{2 m} \frac{d^{2} H}{d \theta^{2}}+\frac{\hbar^{2}}{2 m}\left(\frac{v(v+1)+m^{2}-\frac{1}{4}}{\sin ^{2} \theta}-2 \mu \cot \theta\right) H= \\
& \frac{\hbar^{2}}{2 m}\left(l(l+1)+\frac{1}{4}\right) H
\end{aligned}
$$




$$
\Phi=\sqrt{\frac{1}{2 \pi}} \mathrm{e}^{\mathrm{im} \varphi}
$$

Penyelesaian bagian radial pada poin $\mathrm{d}$, sehingga diperoleh potensial effektif, $V_{e f f}=\frac{\hbar^{2}}{2 m \alpha^{2}}\left(\frac{a(a-1)+l(l+1)}{\sin ^{2}\left(\frac{r}{\alpha}\right)}+\frac{b(b-1)}{\cos ^{2}\left(\frac{r}{\alpha}\right)}\right)+$

$\frac{\hbar^{2}}{2 m \alpha^{2}} l(l+1) d_{0}$

dengan permisalan superpotensialnya,

$\phi(x)=A \tan \left(\frac{r}{\alpha}\right)+B \cot \left(\frac{r}{\alpha}\right)$

Sehingga diperoleh fungsi gelombang tingkat dasar, dengan bentuk, $\psi_{0}^{(-)}=$

$C\left(\cos \left(\frac{r}{\alpha}\right)\right)^{b}\left(\sin \left(\frac{r}{\alpha}\right)\right)^{\sqrt{a(a-1)+l(l+1)+\frac{1}{4}+\frac{1}{2}}}$

dan fungsi gelombang tereksitasi tingkat pertama, dengan bentuk,

$\psi_{1}^{(-)}\left(x ; a_{0}\right)=\frac{\hbar}{\alpha \sqrt{2 m}}\left\{\left[(2 b+1)\left(\sin \left(\frac{r}{\alpha}\right)\right)^{2}-\right.\right.$

$\left.\left.\left(2 a^{\prime}+1\right)\left(\cos \left(\frac{r}{\alpha}\right)\right)^{2}\right]\right\}$

$\left\{C\left(\cos \left(\frac{r}{\alpha}\right)\right)^{b}\left(\sin \left(\frac{r}{\alpha}\right)\right)^{\sqrt{a(a-1)+l(l+1)+\frac{1}{4}}+\frac{1}{2}}\right\}$

Dan dengan proses yang sama pada poin a, maka diperoleh spektrum energi untuk sistem Coulomb yaitu,

$E_{n_{r}}=\frac{\hbar^{2}}{2 m \alpha^{2}}\left(\sqrt{a(a-1)+l(l+1)+\frac{1}{4}}+\right.$

$\left.b+2 n_{r}+\frac{1}{2}\right)^{2}+\frac{\hbar^{2}}{2 m \alpha^{2}} l(l+1) d_{0}$

dari pers.(60), diperoleh grafik tingkat energi untuk potensial non-sentral Poschl-Teller plus Rosen morse trigonometri, dalam bentuk

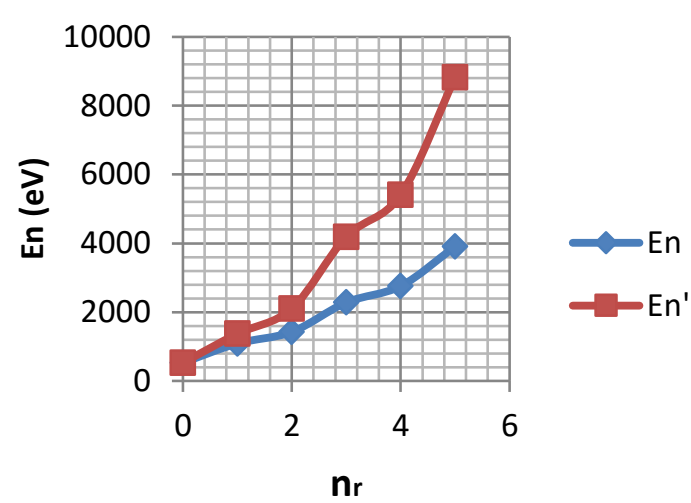

Gambar 4.Grafik tingkat energi potensial non sentral Rosen Morse trigonometri plus Poschl Teller, dengan $v=$ $0,1,2,3, \ldots \mathrm{m}=0, n_{l}=0,1,2,3 \ldots$, dan $n_{r}=0,1,2,3,4,5$.

Gambar 4, menunjukkan bahwa harga bilangan kuantum orbital dipengaruhi oleh nilai $l$, dengan En adalah energi tidak terganggu dan En' adalah energi terganggu. Nilai $l$ menentukan kapasitas gangguan dari potensial Rosen Morse, dalam hal ini, semakin besar harga $l$, potensial Poschl Teller akan mengalami gangguan yang semakin besar dari potensial Rosen Morse.

\section{SIMPULAN DAN SARAN}

Berdasarkan pembahasan, dapat disimpulkan bahwa:

1. Potensial non sentral kombinasi dari potensial Poschl Teller Trigonometri plus potensial Rosen Morse, Coulomb, dan Osilator Harmonik 3D, serta kombinasi potensial Rosen Morse plus Poschl Teller untuk kelompok potensial shape invariance dapat diselesaikan dengan metode SUSY.

2. Hasil penyelesaian secara analitik dari Potensial non-sentral pada poin 1, dapat divisualisasikan dengan simulasi komputasi menggunakan software Maple 12. 
Berdasarkan simpulan dan implikasi sebelumnya, dapat dikemukakan beberapa saran sebagai berikut:

1. mengkaji bentuk potensial lain dan menyimpulkan potensial mana yang menghasilkan tingkatan energi yang lebih tinggi.

2. Pengkajian lebih mendalam hasil teori terhadap Fisika terapan, misalnya material.

\section{DAFTAR PUSTAKA}

Ballentine, L. E. (2014). Quantum mechanics: a modern development. World Scientific Publishing Co Inc.

Cari, C., Suparmi, S., \& Saregar, A. (2016). Solution of the Schrödinger Equation for Trigonometric Scarf Plus PoschlTeller Non-Central Potential Using Supersymmetry Quantum Mechanics. INDONESIAN

JOURNAL OF APPLIED PHYSICS, 4(01), 1-13.

Chen, C. Y., \& Dong, S. H. (2005). Exactly complete solutions of the Coulomb potential plus a new ring-shaped potential. Physics Letters A, 335(5), 374-382.

Chen, G. (2005). Solution of the KleinGordon for exponential scalar and vector potentials. Physics Letters A, 339(3), 300-303.

Combescure, M., Gieres, F., \& Kibler, M. (2004). Are $\mathrm{N}=1$ and $\mathrm{N}=2$ supersymmetric quantum mechanics equivalent?. Journal of Physics A: Mathematical and General, 37(43), 10385.

Dutt, R., Gangopadhyaya, A., \& Sukhatme, U. P. (1997). Noncentral potentials and spherical harmonics using supersymmetry and shape invariance. American Journal of Physics, 65(5), 400-403.
El Kinani, A. H., \& Daoud, M. (2001). Coherent states à la KlauderPerelomov for the Pöschl-Teller potentials. Physics

Letters A, 283(5), 291-299.

Goudarzi, H., \& Vahidi, V. (2011). Supersymmetric Approach for Eckart Potential Using the NU Method. Adv. Studies Theor. Phys, 5(10), 469-476.

Gönül, B., \& Zorba, İ. (2000). Supersymmetric solutions of noncentral potentials. Physics Letters A, 269(2), 83-88.

Gönül, B., \& Kocak, M. (2005). Systematic search of exactly solvable non-central potentials. Modern Physics Letters A, 20(05), 355-361.

Ikhdair, S. M., \& Sever, R. (2007). Polynomial solution of noncentral potentials. International Journal of Theoretical Physics, 46(10), 2384-2395.

Aktas, M. (2007). Exact solutions to a new generalized non-central potential in three dimensions. arXiv preprint quantph/0701063.

Meyur, S., \& Debnath, S. (2009). Solution of the Schrödinger equation with Hulthén plus Manning-Rosen potential. Lat. Am. J. Phys. Educ, 3(2), 300-306.

Meyur, S., \& Debnath, S. (2010). Eigen spectra for Woods-Saxon plus Rosen-Morse potential. Lat. Am. J. Phys. Educ. Vol, 4(3), 587.

Mustafa, M., \& Kais, S. (2009). A Venn diagram for supersymmetric, exactly solvable, shape invariant, and Infeld-Hull factorizable potentials. arXiv preprint arXiv:0911.4206.

Xian-Quan, H., Guang, L., Zhi-Min, W., Lian-Bin, N., \& Yan, M. (2010). Solving Dirac equation with new ring-shaped 
harmonic oscillator potential. Communications in Theoretical Physics, 53(2), 242.

Dutt, R., Khare, A., \& Sukhatme, U. P. (1988). Supersymmetry, shape invariance, and exactly solvable potentials. American Journal of Physics, 56(2), 163-168.

Salehi, H. (2011). Determine the eigen function of Schrodinger equation with non-central potential by using NU method. Applied Mathematics, 2(08), 999.

Salehi, H. (2011). Determine the eigen function of Schrodinger equation with non-central potential by using NU method. Applied Mathematics, 2(08), 999.

Sadeghi.J and Pourhassan. B, 2008, Sadeghia, J., \& Pourhassan, B. (2008). Exact Solution of The Non-Central Modified Kratzer Potential Plus a Ring-Shaped Like Potential By The Factorization Method. Electronic Journal of Theoretical Physics, 5(17).

Saregar, A., Suparmi, A., Cari, C., \& Yuliani, H. (2013). Analysis of Energy Spectra and Wave Function of Trigonometric Poschl-Teller plus Rosen-Morse Non-Central Potential Using Supersymmetric Quantum Mechanics
Approach. RESEARCH

INVENTY: International Journal Of Engineering And Science, 2(3), 14-26.

Saregar, A. (2015). Solution Of Schrödinger Equation For PoschlTeller Plus Scarf Non-Central Potential Using Supersymmetry Quantum Mechanics Aproach. Jurnal Ilmiah Pendidikan Fisika Al-Biruni, 4(1), 25-35.

Sohnius, M. F. (1985). Introducing Supersymmetry (Cambridge CB3 9EW. NHC: England.

Suparmi, A., Cari, C., Handhika, J., Yanuarief, C., \& Marini, H. (2012). Approximate Solution of Schrodinger Equation for Modified Poschl-Teller plus Trigonometric Rosen-Morse NonCentral Potentials in Terms of Finite Romanovski Polynomials. IOSR Journal of Applied Physics (IOSRJAP), 2(2), 43-51.

Suparmi, A. (1992). Desertation, Semiclassical SUSY approace in Quantum Mechanics, Department of Physics, Suny at Albany.

Yasuk. F., Berkdemir C., Berkdemir A. (2005). Phys. A: Math. Gen, 38, 6579-6586. 